\title{
Adoption of improved technologies by the cattle famers of Batticaloa district
}

\author{
Thivahary Geretharan ${ }^{1}$, C. Sivayoganathan ${ }^{2}$ and M. M. Mahusoon ${ }^{3}$ \\ ${ }^{1}$ Department of Agricultural Economics, Faculty of Agriculture, Eastern University, Sri Lanka \\ ${ }^{2}$ Department of Agricultural Extension, Faculty of Agriculture, University of Peradeniya, Sri Lanka \\ ${ }^{3}$ Department of Animal Science, Faculty of Agriculture, Eastern University, Sri Lanka
}

\begin{abstract}
The study area Batticaloa occupies the central part of the Eastern Province. The District is divided into 14 administrative divisions and agricultural activities are occurring in all the divisions. Cattle are the most important livestock in the district and play a major role in the livelihood of the small farmers. The present study was undertaken to find out the extent of adoption of improved cattle management practices and to identify the factors that influence adoption of improved cattle technologies. A total of 120 farmers were randomly selected from two veterinary ranges in the district and personal interview method was employed to collect data. The study revealed that, cattle farmers in the Batticaloa district had enough knowledge on disease control, modern waste management, deworming, feeding balanced diet, control of parasites and improved castration methods. They had a fair knowledge on the areas of improved breeds, artificial insemination and modern housing methods. Practices like disease control, vaccination, deworming and control of parasites were highly adopted by them. The level of education of cattle farmers significantly influenced the adoption of improved technologies. Family size of the cattle farmers did not significantly influence the adoption of technologies. Various technical, economical, sociopsychological and infra-structural factors were affected the adoption of the improved cattle technologies.
\end{abstract}

Keywords: Adoption, cattle farmers, improved technologies

\section{Introduction}

Animal husbandry has a specialized significance as it can play an important role in improving the socio economic status of the population in the Batticaloa District. In most cases livestock is the source of cash income for the subsistence farmers as well as endurance of family purchasing power in the event of unprofitable crop cultivation due to unforeseen reasons. This immense potential is limited by the traditional and tenure system and subsistence farming practices (traditional technologies) that unfortunately seldom assure or generate adequate returns which can promote the development of more commercially oriented livestock production systems (Nell et al., 1998). If agricultural technologies developed for farmers in developing countries are not transferred in appropriate manner and adopted accordingly, all the efforts by the researchers who developed new technologies would be in vain. This is probably why transfer and adoption of new technologies is perhaps one of the most popular research topics about and controversial topics in developing agriculture (Nell et al., 1998). Technology transfer and development is not a new concept, it has been around since mankind discovered things that they did not know before (Finlayson, 1995). A farmer is a rational decision maker who normally strives for a better standard of living and seeks ways of adopting new technologies to accomplish this goal (Nell et al., 1998).

Livestock is an integral component of the rural economy of the Eastern Province of Sri Lanka. 
Batticaloa district in the Eastern Province provides a strong resource base for the livestock industry. There were about 165,000 heads of neat cattle and buffaloes in Batticaloa district and daily milk production was about 18,000 - 200,000 litres of milk in 2008 (Statistical Handbook of Batticaloa District, 2009).

Two decades long civil war had caused loss of lives, displacement of people, loss of assets, etc,. This had major negative impact on income level of the people and the behavioural changes in socioeconomic and cultural aspects. Batticaloa district is a high potential area for cattle production with the availability of grazing lands. There is a need to identify the factors that contribute to the adoption of new livestock technologies as well as those that represent main constraints for the diffusion / adoption process. This type of research is essential for policy formulation to develop the livestock sector and alleviate poverty in rural areas of the country. The study was undertaken with the following objectives:

- to find out the extent of adoption of improved cattle production technology and

- to identify the factors that influence the adoption of cattle production technology by cattle farmers

\section{Methodology}

This study was carried out in Batticaloa district of the Eastern Province. The population of this study consisted of cattle farmers from two veterinary ranges selected based on the distribution of the cattle farmers. The selected veterinary ranges are Kaluwanchikudy and Chenkalady. Three villages were randomly selected from each of the selected veterinary ranges. Twenty cattle farmers were randomly selected from each village. Thus a total of 120 cattle farmers were randomly selected for this study.

Structured questionnaire was developed to obtain relevant information covering the objectives of the study. Adoption level and knowledge level of cattle farmers were studied as dependent variables and the socio-economic characteristics of cattle farmers' were studied as independent variables.
Before going to final data collection, the interview schedule was pre-tested using 20 non-respondent cattle farmers of Batticaloa and accordingly appropriate changes were made. Interviews were conducted using an interview schedule with the selected 120 cattle farmers. Statistical analysis was done with the help of SPSS 14.0 package. Data were analysed by employing t-test for mean comparisons and Chi-square for testing associations.

\section{Results and Discussion}

\section{Socio-economic Characteristics of Livestock Farmers}

The study revealed that most of the people involved in cattle rearing in Batticaloa district were males, between 36 to 50 years. Majority of the farmers $(72.5 \%)$ had herd size ranging from 1 to 10 and had the farming experience $(67.5 \%)$ from 6 years to 10 years. Around $84 \%$ of the cattle farmers reared cattle for milk and meat purpose and majority of them reared local breeds. Most of the farmers $(75 \%)$ in the district had their membership with some livestock organization. By having membership, farmers were able to get a wide range of benefits such as buying agricultural supplies at lower prices, commercialization of products, representation in the sector etc.

\section{Knowledge and Adoption of Practices Knowledge Level}

The total score for each improved technology was calculated by scoring each variable viz, low, medium and high as, 1,2 and 3 respectively and multiplying each score by number of respondents who obtained the particular point and then by adding up the total scores obtained for each improved technology. 
Table 1. Knowledge level on improved technologies

\begin{tabular}{|c|c|c|c|c|c|c|c|c|}
\hline \multirow[t]{2}{*}{$\begin{array}{l}\text { Improved } \\
\text { Technologies }\end{array}$} & \multicolumn{2}{|l|}{ Low } & \multirow{2}{*}{$\begin{array}{l}\text { Medium } \\
\text { Frequency }\end{array}$} & \multicolumn{2}{|c|}{ High } & & \multirow[t]{2}{*}{$\begin{array}{l}\text { Total } \\
\text { Score } \\
\end{array}$} & \multirow[t]{2}{*}{$\begin{array}{l}\text { Mean } \\
\text { Score } \\
\end{array}$} \\
\hline & Frequency & $\%$ & & $\%$ & Frequency & $\%$ & & \\
\hline Artificial insemination & 86 & 71.7 & 29 & 24.2 & 05 & 4.2 & 159 & 1.33 \\
\hline Modern housing methods & 99 & 82.5 & 19 & 15.8 & 02 & 1.7 & 143 & 1.19 \\
\hline Improved breeds & 01 & 0.8 & 25 & 20.8 & 94 & 78.3 & 243 & 2.03 \\
\hline Feeding balanced diet & 00 & 0.0 & 26 & 21.7 & 94 & 78.3 & 334 & 2.78 \\
\hline Control of parasites & 00 & 0.0 & 28 & 23.3 & 92 & 76.7 & 332 & 2.77 \\
\hline Disease control & $\therefore 03$ & 2.5 & 12 & 10.0 & 105 & 87.5 & 342 & 2.85 \\
\hline Deworming & 00 & 0.0 & 24 & 20.0 & 96 & 80.0 & 336 & 2.80 \\
\hline Vaccination & 03 & 2.5 & 45 & 37.5 & 72 & 60.0 & 309 & 2.58 \\
\hline Improved castration method & ds 05 & 4.2 & 33 & 27.5 & 82 & 68.3 & 17 & 2.64 \\
\hline Modern waste management & t. 02 & 1.7 & 19 & 15.8 & 99 & 2.5 & 337 & 2.81 \\
\hline
\end{tabular}

Table 1 clearly explains the knowledge level of cattle farmers on selected improved technologies. Cattle farmers in the Batticaloa district have enough knowledge on disease control (mean score 2.85 ), modern waste management (mean score 2.81 ), deworming (mean score 2.80 ), feeding balanced diet (mean score 2.78), control of parasites (mean score 2.77) and improved castration methods (mean score 2.64). And they got fair knowledge on the areas of improved breeds, artificial insemination and modern housing methods.

\section{Table 2. Overall knowledge level}

\begin{tabular}{lcc}
\hline Knowledge Level & Frequency & Percent \\
\hline Low $(0-33 \%)$ & 75 & 62.5 \\
Medium $(34-66 \%)$ & 36 & 30.0 \\
High $(67-100 \%)$ & 09 & 7.5 \\
\hline
\end{tabular}

Considering the overall knowledge level of the cattle farmers, $62.5 \%$ had low level of knowledge related to the improved cattle technologies and $30 \%$ had medium level of knowledge on improved cattle technologies. Only around $7.5 \%$ of the farmers had high level of knowledge on improved cattle technologies (Table 2).

\section{Adoption Level}

Table 3 shows how cattle farmers in Batticaloa district adopted some selected improved technologies. Practices such as disease control (mean score 2.88), vaccination (mean score 2.79), deworming (mean score 2.75) and control of parasites (mean score 2.10 ) were highly adopted by the cattle farmers in Batticaloa district.

Table 3: Adoption level of improved technologies

\begin{tabular}{|c|c|c|c|c|c|c|c|c|}
\hline \multirow{2}{*}{$\begin{array}{l}\text { Improved • } \\
\text { Technologies } \\
\end{array}$} & \multicolumn{2}{|l|}{ Low } & Medium & \multicolumn{2}{|c|}{ High } & \multirow[b]{2}{*}{$\%$} & \multirow[t]{2}{*}{$\begin{array}{l}\text { Total } \\
\text { Score }\end{array}$} & \multirow[t]{2}{*}{$\begin{array}{l}\text { Mean } \\
\text { Score }\end{array}$} \\
\hline & Frequency & $\%$ & Frequency & $\%$ & Frequency & & & \\
\hline Artificial insemination & 78 & 65.0 & 35 & 29.2 & 07 & 5.8 & 169 & 1.41 \\
\hline Modern housing methods & 84 & 70.0 & 29 & 24.2 & 07 & 5.8 & 163 & 1.36 \\
\hline Improved breeds & 81 & 67.5 & 30 & 25.0 & 09 & 7.5 & 168 & 1.40 \\
\hline Feeding balanced diet & 73 & 60.8 & 33 & 27.5 & 14 & 11.7 & 181 & 1.54 \\
\hline Control of parasites & 03 & 2.5 & 102 & 85.0 & 15 & 12.5 & 252 & 2.10 \\
\hline Disease control & 00 & 0.0 & 15 & 12.5 & 105 & 87.5 & 345 & 2.88 \\
\hline Deworming & 07 & 5.8 & 16 & 13.3 & 97 & 80.8 & 330 & 2.75 \\
\hline Vaccination & 03 & 2.5 & 39 & 15.8 & 98 & 81.7 & 335 & 2.79 \\
\hline Improved castration methods & s 81 & 67.5 & 37 & 30.8 & 02 & 1.7 & 161 & 1.34 \\
\hline Modern waste management & 94 & 8.3 & 24 & 20.0 & 02 & 1.7 & 148 & 1.23 \\
\hline
\end{tabular}


Some of the improved technologies such as modern waste management (mean score 1.23), improved castration methods (mean score 1.34), modern housing methods (mean score 1.36), improved breeds (mean score 1.40), artificial insemination (mean score 1.41) and feeding balance diets (mean score 1.31 ) were poorly adopted.

\section{Table 4. Overall adoption level}

\begin{tabular}{lcc}
\hline Knowledge Level & Frequency & Percent \\
\hline Low $(0-33 \%)$ & 92 & 76.7 \\
Medium $(34-66 \%)$ & 23 & 19.2 \\
High $(67-100 \%)$ & 05 & 4.2 \\
\hline
\end{tabular}

Table 4 shows the overall adoption level of improved cattle technologies among the cattle farmers in Batticaloa district. Majority (76.7\%) of the respondents fall under the group of low

\section{Factors affecting Adoption of Improved Technologies}

There are several factors contributing towards the adoption of improved cattle management technologies. Those factors were categorized as technical factors, economical factors, sociopsychological factors and infra-structural factors.

\section{Technical Factors}

Majority of the respondents (more than 90\%) indicated that the following technical factors affected the adoption of improved technologies (Table 5): adopters. And around 19\% of the respondents come under the category of medium adopters and only $4 \%$ of the farmers had the high adoption level of improved cattle technologies.
- Poor conception rate ( poor results of AI)

- Non-availability of semen at AI centre

Non-availability of veterinary medicines in the centre

Lack of knowledge of common contagious diseases, their symptoms and prevention measures

- Side effects of vaccine such as abortion and decrease in milk production after vaccination

Lack of knowledge about cheap and scientific housing of cattle.

\section{Table 5. Technical factors affecting adoption of improved technologies}

\begin{tabular}{lcc}
\hline \multicolumn{1}{c}{ Factors } & Frequency & $\%^{*}$ \\
\hline Lack of knowledge about cheap and scientific housing of cattle & 116 & 96.7 \\
Too much repeated breeding through AI & 115 & 95.8 \\
Lack of knowledge about recommended feeding practices & 114 & 95.0 \\
Lack of knowledge of common contagious diseases, their symptoms and & & \\
preventive measures & 114 & 95.0 \\
Poor skill of Inseminator & 113 & 94.2 \\
Non-availability of semen at AI centre & 113 & 94.2 \\
Side reaction of vaccine such as abortion and decrease in milk production after & 113 & 94.2 \\
vaccination etc., & 112 & 93.3 \\
Non-availability of Veterinary medicines in the centre & 03 & 2.5 \\
Poor conception rate i.e poor result of AI & & \\
\hline
\end{tabular}

*Multiple Responses 


\section{Economic Factors}

\section{Table 6: Economic factors affecting adoption of improved technologies}

\begin{tabular}{llc}
\hline \multicolumn{1}{c}{ Factors } & Frequency & $\%^{*}$ \\
\hline Reluctance of the milk trade to pay remunerative price for the milk & 113 & 94.2 \\
Lack of credit supply for purchase of crossbred animals & 114 & 95.0 \\
Lack of money for house construction & 112 & 93.3 \\
Higher cost of veterinary medicines & 111 & 92.5 \\
Ignorance of cattle insurance facilities and lack of money for the insurance of & 111 & 92.5 \\
cattle & 110 & 91.7 \\
Poor market value of crossbred male calves & 02 & 1.7 \\
High cost of feed & 02 & 1.7 \\
Lack of interest in selling milk through dairy co-operative societies (unavailability & & \\
of Co-op societies) & &
\end{tabular}

*Multiple Responses

Majority of the respondents (more than 90\%) indicated that the following economic factors influenced the adoption of improved technologies (Table 6):

- High cost of feed

- Lack of money for house construction

- Higher cost of veterinary medicines

- Lack of credit supply for purchase of crossbred animals

- Ignorance of cattle insurance facilities and lack $\dot{k}$ of money for the insurance of the cattle
- Reluctance of the milk trade to pay remunerative price for the milk.

\section{Socio-psychological Factors}

Majority of the respondents agreed that the following two socio-psychological factors affected the adoption of the improved cattle technologies (Table 7):

- Favourable attitude towards natural services compared to AI $(95.8 \%)$

- Inseminator performs AI with the consideration of not displeasing the owner even when ideal state of heat is already over (95.0)

Table 7. Socio-psychological factors affecting adoption of improved technologies

\begin{tabular}{|c|c|c|}
\hline Factors & Frequency & $\% *$ \\
\hline Inseminator performs AI with the consideration of not displeasing the owner & 115 & 95.8 \\
\hline even when ideal state of heat is already over & 114 & 95.0 \\
\hline Favourable attitude towards natural services compared to AI & & \\
\hline $\begin{array}{l}\text { Prejudice against the draught capacity of crossbred male subjected to poor } \\
\text { nutrition level and management }\end{array}$ & 04 & 3.3 \\
\hline $\begin{array}{l}\text { Favourable attitude of stock man towards village leaders and progressive } \\
\text { farmers Unfavourable attitude towards selling of milk which becomes a }\end{array}$ & 02 & 1.7 \\
\hline barrier to the rearing of high yielding milk animals & 02 & 107 \\
\hline $\begin{array}{l}\text { Favourable attitude towards growing grain and other cash crops rather than } \\
\text { growing fodder crops }\end{array}$ & 01 & 08 \\
\hline Lack of appreciation and medicines and having faith in indigenous treatment & 00 & 0.0 \\
\hline
\end{tabular}

*Multiple Responses

\section{Infra-structural factors}

More than $90 \%$ of the respondents agreed that all the factors presented in Table 8 influenced the adoption of cattle improved technologies. 
Table 8. Infra-structural factors affecting adoption of improved technologies

\begin{tabular}{llc}
\multicolumn{1}{c}{ Factors } & Frequency & \%* \\
\hline Lack of communication regarding the services and other facilities available & & \\
for agro-dairy husbandry at the centres & 115 & 95.8 \\
Lack of frequent technical supervision & 115 & 95.8 \\
Lack of timely and adequate supply of semen and AI accessories & 113 & 94.2 \\
Complaints against staff - not yielding good results & 113 & 94.2 \\
Lack of trained veterinary staff & 113 & 94.2 \\
Untimely supply of inputs and other materials & 112 & 93.3 \\
Closing the Veterinary offices on Saturdays \& other holidays & 111 & 92.5 \\
Location of dispensary at distant place & 109 & 90.8 \\
\hline
\end{tabular}

*Multiple Responses

\section{Association between Educational Level and Adoption Level}

Table 9 shows significant association between level of education of cattle famers and adoption level. Among the farmers who possess low level of education, $89.0 \%$ were low adopters of improved cattle technologies and $11.0 \%$ of the respondents were high adopters of cattie improved technologies. Among the farmers with high level of education, $66.7 \%$ of the respondents were low adopters and $33.3 \%$ were high adopters of cattle improved technologies. Thus, the level of education significantly influenced $(p<0.05)$ the adoption of improved technologies. Formal education broadens the mind and makes a farmer more inquisitive and willing to try extended innovations.

Table 9. Association between education level and adoption level

\begin{tabular}{lccc}
\hline & \multicolumn{3}{c}{ Adoption Level } \\
\cline { 2 - 4 } Education & Low $(0-33 \%)$ & High $(34-100 \%)$ & Total \\
Low $(0-2.0)$ & $65(89.0)$ & $08(11.0)$ & 73 \\
Medium $(2.1-4.0)$ & $21(55.3)$ & $17(44.7)$ & 38 \\
High $(4.1-6.0)$ & $06(66.7)$ & $03(33.3)$ & 09 \\
\hline Total & 92 & 28 & 120 \\
\hline
\end{tabular}

$X^{2}=16.48, \mathrm{p}<0.05$, Row percentages are shown in parentheses.

\section{Assnciation between Family size and} Adoption level

Considering the association between family size and adoption level, among the cattle farmers having less than three members in their family, $81.0 \%$ of the respondents were low adopters of the cattle improved technologies and 19.0\% were high adopters of cattle modern technologies. Among the farmers who had three to seven family members, $75.3 \%$ were low adopters and $24.7 \%$ were high adopters of cattle modern technologies. Also, farmers with higher than seven members in their family, $80.0 \%$ were low adopters and $20.0 \%$ were high adopters of cattle modern technologies. Family size did not significantly influence the adoption level $\left(X^{2}=0.37, \mathrm{p}>0.05\right)$. As family size increases, a farmer progressively becomes unwilling to take risks associated with adoption of innovations. This is probably owing to the fact that if the adopted innovation spelis disaster for a farm, both the farmer and his family are put into a state of jeopardy regarding their food security and access to other needs.

\section{Association between Membership with Livestock Organization and Adoption level}

Considering the association between cattle farmers who are members or non-members of livestock organization and adoption level, among the cattle farmers who were members of livestock organization, $83.3 \%$ were low adopters and $16.7 \%$ were high adopters of cattle modern technologies. 
And among the cattle farmers who were nonmembers of livestock organization, $56.7 \%$ were low adopters and $43.3 \%$ were high adopters of cattle improved technologies. There was no significant association between adoption level and membership with livestock organization $\left(X^{2}=0.06\right.$, $\mathrm{p}>0.05$ ).

\section{Differences between Farmers with or without Membership in Livestock related Organization}

Table 10 shows the independent samples t-test regarding the demographic and other characteristics of cattle farmers having membership and non-membership with livestock related organizations. Demographic and other characteristics such as age, farming experience, age. herd size, and family size were taken into consideration.

There is a significant difference between the cattle farmers who were having membership in livestock related organizations and not having membership in livestock related organizations and their age. Hossain and Crouch (1992), and Talawar and Hirevenkangoudar (1989) reported that there were significant positive correlations between farmers' age and adoption of modern farming practices in Bangladesh and age and adoption of modern poultry management practices in India, respectively. However, in this study the members who had higher age did not show higher adoption than non-members who had comparatively low

Table 10. Differences between farmers with or without membership in livestock related organizations

\begin{tabular}{|c|c|c|c|c|}
\hline \multirow{3}{*}{ Variable } & \multicolumn{2}{|c|}{ Mean values } & \multirow{2}{*}{ T value } & P value \\
\hline & & & & \\
\hline & Membership & No membership & & \\
\hline Age (years) & 48.37 & 39.97 & 4.132 & $.000^{*}$ \\
\hline Monthly income (Rs.) & 4086.67 & 703.33 & 2.301 & $.024^{*}$ \\
\hline Herd size & 9.89 & 9.50 & 0.180 & .858 \\
\hline Family size & 5.06 & 5.00 & 0.154 & .384 \\
\hline Farming experience (years) & 14.57 & 11.17 & 2.185 & $.032^{*}$ \\
\hline
\end{tabular}

*Significant at $5 \%$.

Similarly, there is a significant difference between cattle farmers who were having membership in livestock related organizations and not having membership in livestock related organizations and farming experience. This means cattle farmers with more farming experience had membership in livestock related organizations. This is probably because farmers who have more experience in cattle farming are aware about the benefits of having membership in a livestock related organization compared to the farmers with less experience in cattle farming.

Characteristics such as family size and herd size are not significantly different between cattle farmers who are having membership with livestock related organizations and those who are not having membership with livestock related organizations. This implies that there are no barriers to cattle farmers with less number of cattle to join the livestock related organizations.

\section{Conclusions}

The study has shown that most of the people involved in cattle rearing in Batticaloa district were males, between 36 to 50 years. Most of the farmers $(72.5 \%)$ had herd size ranging from 1 to 10 and had the farming experience from 6 years to 10 years. Most of the farmers (75\%) in the district had their membership with some livestock organization. By having membership farmers were able to get a wide range of benefits like buying agricultural supplies at lower prices, commercialization of products, representation in the sector etc. Cattle farmers in the Batticaloa district have enough knowledge on disease control, modern waste management, deworming, feeding balanced diet, control of parasites and improved castration method. Among them, practices like disease control, deworming and control of parasites were highly adopted by the cattle farmers in the Batticaloa district. Therefore, it is necessary to intensify the extension efforts to increase their 
knowledge level and adoption of recommended technologies, which would help in increasing the production. The level of education of cattle farmers significantly influenced the adoption of cattle improved technologies. Family size of cattle farmers did not significantly influence the adoption of cattle improved technologies. There were significant differences observed between the cattle farmers who were having membership in livestock related organization and not having membership in livestočk related organization with respect to age, farming experiencé and monthly income.

\section{References}

Finlayson, (1995). Transferring technology in developing countries. In Doward, P. T (Ed.) The world of Farm Management: An intervention exchange. Proceedings of Tenth International Farm Management Congress at the University of Readings.
Hossain, S. M. A. and B.R. Crouch (1992) Patterns and determinants of adoption of farm practices: Some evidence from Bangladesh. Agricultural Systems, 38:1-15.

Nell, W. T., H.D. Schalkwyk van., J.H. Sanden., L. Schwalbach and C.J. Bester (1998). Adoption of services by sheep and goat farmers in Qwaqwa, Agrekon, 37 (4): 418 434

Statistical Handbook (2009), Batticaloa district, Sri Lanka.

Talawar, S. and L.V. Hirevenkanagoudar (1989). Factors of adoption of poultry management practices. Indian Journal of Extension Education, 25(3 and 4): 67-73. 